\title{
Pesquisa-ação para inclusão digital de professores e alunos: um projeto piloto usando Google Docs
}

\author{
Miriam Noering Klemann ${ }^{1}$, Clevi Elena Rapkiewicz ${ }^{1}$ \\ ${ }^{1}$ UFRGS, Av. Paulo Gama, 110 - Porto Alegre/RS - 90040-060 - Brazil \\ \{miriamklemann, clevirap\}@gmail.com
}

Resumo: Vivemos atualmente na assim chamada Sociedade da Informação, na qual a inclusão de diferentes profissionais no mundo digital é essencial, particularmente no caso de professores. Uma das dificuldades dos processos de inclusão digital é a escolha dos instrumentos e ferramentas a serem utilizados. Neste artigo, apresentamos a análise do Google Docs como ferramenta possível para integrar processos de inclusão digital tanto de professores quanto de alunos, a partir de uma experiência prática em uma cidade do interior do RS. A experiência mostra que trata-se de uma ferramenta fácil de usar e com amplo potencial, mas cujo uso em larga escala depende, ainda, da questão da infra-estrutura de Internet nas escolas.

Palavras- Chave: inclusão digital, formação de professores, autoria

\section{Introdução}

A forma mais adequada de se incluir digitalmente e "formar indivíduos no mundo em rede conduzido pela Internet, é tornando-os capazes de se auto-programar, gerar conhecimentos e utilizá-los” (CASTELLS, 2003, p. 227). Mas, para que isso ocorra, conforme o autor - deve ser implantado um modelo de ensino, que forme este indivíduo para ter capacidade autônoma para aprender e pensar. Para este autor, os "poderosos" têm condições de criar e recriar tecnologias, mas nem sempre os usuários têm condições de acompanhar as mudanças e, se não dispõem dos recursos tecnológicos oferecidos, podem ser excluídos.

Porém, incluir digitalmente é mais do que o acesso à informação. De acordo com Fagundes (2004), a "inclusão digital não é só o amplo acesso à tecnologia, mas a apropriação dela na resolução de problemas”. Para esta autora, os computadores são "máquinas de aprender porque permitem, a cada aluno, provocar experiências, observar experiências, interferir nelas e compartilhá-las com outras crianças e com professores”.

A fim de tornar os alunos usuários familiarizados com os recursos disponíveis nos computadores, eles precisam usar a informática e não, simplesmente ter aula de informática (COSCARELLI, 2005). Para esta autora, os recursos da informática são muito sedutores, além de imprescindíveis para a formação de um cidadão letrado. A UNESCO (2009) destaca a importância de "ajudar os alunos a adquirirem habilidades em TIC no contexto de seus cursos" bem como fazer com que eles demonstrem e ensinem suas habilidades em TIC para os outros.

Desde 2005, o Centro de Estudos sobre as Tecnologias da Informação e da Comunicação (CETIC.br) publica pesquisas sobre a disponibilidade e uso da Internet no Brasil. Esses estudos são referência para a elaboração de políticas públicas que 
garantam o acesso da população às Tecnologias da Informação e da Comunicação (TICs), assim como, para monitorar e avaliar o impacto socioeconômico das TICs.

Dos domicílios entrevistados no período setembro/novembro de 2010, sobre o tipo de computador presente no domicílio, observa-se que na região Sul, 42\% possuem computador. Destes, 85\% possuem Computador de mesa (Desktop / PC) e 27\% Computador portátil (laptop, notebook).

\begin{tabular}{|c|c|c|c|c|c|c|c|c|c|}
\hline \multirow{3}{*}{ Grandes Regiões } & \multicolumn{9}{|c|}{ Proporção de domicilios com computador (\%) } \\
\hline & \multicolumn{6}{|c|}{ Área Urbana } & \multicolumn{3}{|c|}{ Total Brasil (Urbano + Rural) } \\
\hline & 2005 & 2006 & 2007 & 2008 & 2009 & 2010 & 2008 & 2009 & 2010 \\
\hline Brasil & 17 & 20 & 24 & 28 & 36 & 39 & 25 & 32 & 35 \\
\hline Norte & 10 & 10 & 13 & 18 & 23 & 27 & 15 & 19 & 23 \\
\hline Nordeste & 9 & 9 & 11 & 14 & 18 & 19 & 11 & 14 & 14 \\
\hline Sudeste & 20 & 24 & 30 & 34 & 45 & 47 & 33 & 43 & 45 \\
\hline Sul & 20 & 25 & 31 & 33 & 43 & 44 & 30 & 40 & 42 \\
\hline Centro-Oeste & 17 & 19 & 26 & 32 & 36 & 43 & 30 & 34 & 40 \\
\hline
\end{tabular}

Figura 1 Domicílios com computador

Fonte: CGI.br: Pesquisa sobre o Uso da tecnologias de Informação e Comunicação - TIC Domicílios 2010

Em relação ao acesso a Internet, apenas 30\% tem acesso em casa. Um dos motivos para a falta de Internet no domicílio nas regiões brasileiras é o custo elevado. Apenas 24\% da população entrevistada tem Renda Familiar acima de 3 salários mínimos. Desta forma, optam em acessar no trabalho, na escola, na casa de outra pessoa (amigo, vizinho ou familiar) ou em centros públicos de acesso gratuito ou pago (Internet café, lanhouse ou similar).

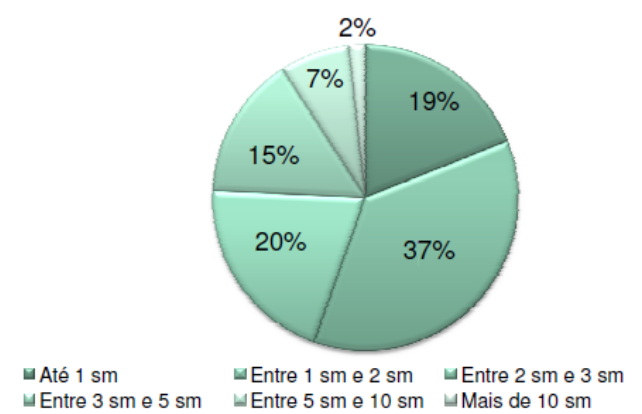

Figura 2 Renda Familiar total Brasil - 2010

Fonte: CGI.br: Pesquisa sobre o Uso da tecnologias de Informação e Comunicação - TIC Domicílios 2010

\begin{tabular}{|c|c|c|c|c|c|c|c|c|c|}
\hline \multirow{3}{*}{ Grandes Regiões } & \multicolumn{9}{|c|}{ Proporção de domicílios com acesso à Internet (\%) } \\
\hline & \multicolumn{6}{|c|}{ Área Urbana } & \multicolumn{3}{|c|}{ Total Brasil (Urbano + Rural) } \\
\hline & 2005 & 2006 & 2007 & 2008 & 2009 & 2010 & 2008 & 2009 & 2010 \\
\hline Brasil & 13 & 14 & 17 & 20 & 27 & 31 & 18 & 24 & 27 \\
\hline Norte & 5 & 6 & 5 & 9 & 13 & 17 & 7 & 10 & 14 \\
\hline Nordeste & 7 & 6 & 7 & 9 & 13 & 15 & 7 & 10 & 11 \\
\hline Sudeste & 16 & 19 & 22 & 26 & 35 & 39 & 25 & 33 & 36 \\
\hline Sul & 15 & 17 & 21 & 23 & 32 & 32 & 20 & 29 & 30 \\
\hline Centro-Oeste & 14 & 13 & 16 & 23 & 28 & 35 & 21 & 25 & 33 \\
\hline
\end{tabular}

Figura 3 Domicílios com Internet

Fonte: CGI.br: Pesquisa sobre o Uso da tecnologias de Informação e Comunicação - TIC Domicílios 2010

Questionados sobre a forma de obtenção de habilidades para o uso do computador, apenas $19 \%$ da região sul responderam que isso ocorreu em uma instituição formal de ensino (escola), o que pode ser explicado em parte pelas faixas 
etárias (parte da população entrevistada não está no sistema formal de ensino), mas, também, pelas condições de acesso a tecnologia nas escolas.

De acordo com o Censo Escolar 2010, o Brasil conta com 51.5 milhões de estudantes matriculados na Educação Básica (Educação Infantil, Ensino Fundamental I, Ensino Fundamental II e Ensino Médio); 43.9 milhões de alunos nas redes públicas de ensino (85.4\%) e 7.5 milhões na rede particular (14.6\%); 1.97 milhões de professores.

Das escolas pesquisadas, 81\% possuem laboratórios de informática. Os 64\% dos professores das escolas pesquisadas apontam que o aluno tem mais conhecimento sobre o uso das TIC. Já $48 \%$ dos professores afirmam ter realizado um curso específico. O principal tipo de apoio percebido pelo professor para o desenvolvimento de seus conhecimentos para o uso das TIC acontece em contatos informais.

Sobre o uso de Computador e Internet em atividades realizadas com os alunos, os resultados apontam que apenas $40 \%$ dos professores utilizam o computador nas suas aulas. Ou seja, se uma parte dos problemas de infraestrutura parece ter sido resolvido, já que apenas 19\% das escolas não teriam laboratório, parece que o problema de usar a infraestrutura ainda procede.

Percebe-se, nesse contexto, a necessidade de aumentar o nível de alfabetização digital no país e fomentar ações das escolas que permitam contribuir para esse aumento. Neste sentido, este artigo analisa uma ação de inclusão digital com professores e alunos de escolas públicas municipais de um município da serra gaúcha ${ }^{1}$, buscando discutir a pertinência do uso da ferramenta Google Docs. Para tanto, o artigo está organizado em 4 seções além da presente introdução. Na seção 2, é apresentada a metodologia. Na seção 3, é apresentado referencial teórico. Na seção 4 são apresentados alguns resultados da ação promovida e na seção 5 são apresentadas algumas considerações finais.

\section{Metodologia}

Nesta seção apresentamos os procedimentos, os sujeitos da pesquisa e os "materiais", por assim dizer, utilizados. A metodologia usada foi a pesquisa-ação. A pesquisa-ação, método qualitativo particular de pesquisa social, enfatiza especificidades, onde o pesquisador detecta um problema em seu meio, buscando estratégias de ação para modificar a situação identificada. Favorece as discussões e a produção cooperativa de conhecimentos específicos sobre a realidade vivida, com foco principal na análise das práticas instituídas no convívio social. Para Thiollent (2007) pesquisa-ação é:

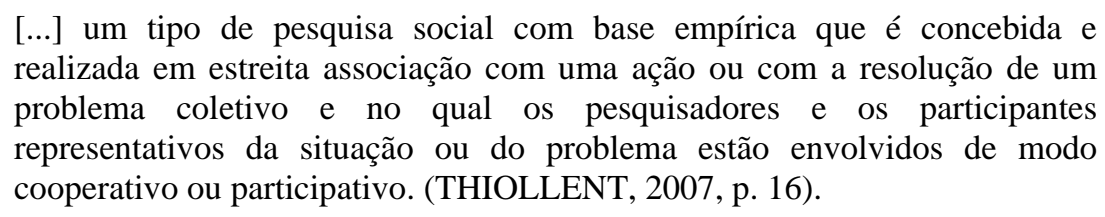

Atualmente muito aplicada na área da educação, a pesquisa-ação serve para elaborar uma análise de uma realidade em que o pesquisador está envolvido, unindo a

\footnotetext{
${ }^{1}$ Projeto financiado pelo CNPq, processo n ${ }^{\circ}$ 5635192010-0
} 
ação à prática. Pode-se apontar uma de suas vantagens na possibilidade de intervir e colocar em prática uma ação inovadora, já no momento que está transcorrendo a pesquisa.

Os dados analisados numa pesquisa-ação são personalizados, restritos e específicos à situação, não podendo ser generalizados, pois somente são válidos ao ambiente estudado. Mesmo tendo limitações, os benefícios da pesquisa-ação estão nos subsídios para a tomada de decisões, sobretudo quando buscam solucionar situações problemáticas. No entanto, melhor do que deixar a problemática no estado em que se encontra, é aplicar soluções imediatas, situações estas que não podem esperar por soluções teóricas. No caso específico da ação apresentada neste artigo, a solução prática imediata foi implementar uma ação com vistas a instrumentalizar os professores para iniciar a melhora do índice de inclusão digital dos mesmos alunos e a inclusão digital de um grupo específico de alunos.

O problema coletivo a ser resolvido foi a iniciar a melhoria da qualificação dos professores responsáveis pelos laboratórios de informática das escolas públicas município atendido e a inclusão digital de alunos. O envolvimento dos integrantes ocorreu de modo participativo e os temas tanto da ação com professores quanto destes com os alunos delineados pela própria comunidade atingida.

A ação foi desenvolvida num município da serra gaúcha que se caracteriza por uma população de cerca de 60 mil habitantes (Censo de 2010) de origem sobretudo de descendentes de colonização italiana, o que determina muitos dos hábitos e cultura do local. O peso da economia local está sustentado sobretudo pela indústria (53\%) (confecções, coureiro-calçadista, metalúrgicas, entre outras), seguido do comércio com $27 \%$.

Os sujeitos da pesquisa são professores de informática de escolas municipais urbanas do citado município. São 18 professores, sendo dois homens e as demais mulheres, com idade que varia de 25 a 52 anos. Um grupo de 262 alunos, de diferentes anos escolares e idades foram envolvidos na ação. Cada professor participante da ação escolheu o grupo de alunos considerando sua própria realidade escolar.

A ferramenta usada também foi definida pelo próprio grupo, após apresentação de possibilidades feita pela equipe do projeto.

A ferramenta sugerida pelos integrantes foi sobre o uso do GoogleDocs. É uma ferramenta Web 2.0 que consiste em um pacote de programas semelhante ao Office da Microsoft ou ao BrOffice da Sun, com o diferencial de que é gratuito, nas nuvens e permite a colaboração na edição de documentos, planilhas, apresentações e formulários.

O GoogleDocs permite criar, armazenar, compartilhar e distribuir documentos de texto em vários formatos, planilhas de cálculo e apresentações de slides (ANTÔNIO, 2010). Utilizando esta ferramenta do Google, pode-se criar atividades de forma colaborativa, como por exemplo criar textos utilizando o Editor de Textos do GoogleDocs, ou seja, uma escrita colaborativa.

A ação realizada com professores foi na forma de oficina e organizada em dois momentos. Primeiramente foi realizada com 18 professores das escolas no município com duração de 8 horas presenciais. Neste encontro foi abordado: [i] o conceito e características - suíte de ferramentas de edição; [ii] criação de contas individuais no Google; [iii] exploração do Google Docs como ferramenta facilitadora de edição e 
compartilhamento (Documento, Apresentação, Planilha, Formulário, Desenho); [iv] atividades práticas a partir de exemplos apresentados do uso em ambiente educacional de Documento e Formulário do Google Docs - priorizando o trabalho em grupo e [v] discussão sobre como utilizar os recursos Google Docs para desenvolver o conteúdo e/ou as habilidades dos alunos.

Já o segundo momento, cada professor realizou atividades com grupos de alunos nas escolas onde atuam e, em alguns casos, foram feitas ações integrando escolas. Exemplos de ações feitas encontram-se na seção 4, logo após a seção referente ao referencial teórico.

\section{Inclusão digital e escrita}

Para o autor Warschauer (2006) o problema atual na abordagem da exclusão digital encontra-se no fato que se imagina que os contextos tecnológico e social podem se separar um do outro. Acredita-se, ingenuamente, que os programas idealizados para solucionar o problema tecnológico melhorarão um ou mais problemas sociais. Porém, conforme o autor, nenhuma tecnologia existe fora de uma estrutura social. Os domínios, tecnológico e social, estão muito entrelaçados e co-existem dentro das organizações, das instituições e da sociedade em geral, fazendo parte delas (BUNGE, 1995).

Para Warschauer (2006), é necessário olhar para o que as pessoas fazem, suas práticas culturais, em lugar de centrar-se simplesmente na inovação tecnológica como fator de mudança. O autor propõe, a partir de suas pesquisas, um conjunto de variáveis interdependentes que participariam do processo de inclusão social via inclusão digital.

É importante enfatizar que “o uso da internet é extremamente diferenciado em termos territoriais, em conformidade com a distribuição desigual de infra-estrutura tecnológica, riqueza e educação do planeta” (CASTELLS, 2003, p. 173).

Partindo para uma visão mais detalhada do processo de inclusão digital e social, Warschauer (2006) propõem quatro variáveis que devem ser analisadas no intuito de contribuir para que o processo de inclusão digital propicie a inclusão social. Estas variáveis são: [i] recursos físicos (computadores e conectividade), [ii] recursos digitais (material digital disponível on-line em termos de conteúdo e linguagem), [iii] recursos humanos (letramento e educação para utilização da informática e da comunicação online) e [iv] recursos sociais (estrutura comunitária, institucional e da sociedade que apóiam o acesso às TICs).

Notar, pois, que Warschauer (2006) usa o termo letramento quando se refere aos recursos humanos. Para Scribner e Cole (1981) letramento é um conjunto de práticas socialmente organizado que usa um sistema de símbolos e tecnologia para a sua produção e reprodução. Não se refere somente ao saber ler e escrever, mas aplicar o conhecimento de leitura e escrita para um fim específico e em um contexto específico de uso. Portanto, a alfabetização é uma das formas de letramento.

A tela do computador, conforme Soares (2002), se apresenta como um novo espaço de escrita e de leitura. Este espaço modifica as formas de interação entre escritor e leitor, entre escritor e texto, entre leitor e texto trazendo novas formas de acesso à informação provocando mudanças e requerendo novas habilidades. Estas práticas de 
escrita e de leitura na tela dão origem a novos processos cognitivos, novas maneiras de ler e escrever, ou seja, um novo letramento, um letramento digital (SOARES,2002).

Alguns estudos vêm contribuindo para a reflexão sobre novas possibilidades de ação pedagógica com a língua escrita em novos suportes tecnológicos, na perspectiva de se repensarem metodologias de trabalho que favoreçam a formação de sujeitos letrados (GOULART, 2005). A leitura e a escrita na tela requerem um sistema de convenções diferente daquele que regula aquelas atividades em folha de papel. Nota-se que as mudanças de relação entre o leitor e o material escrito determinadas pela tecnologia alteram também o próprio modo de significação - antes, por exemplo, era impossível ler e escrever num mesmo momento porque as duas mãos estavam ocupadas (ou segurando material, ou escrevendo). Logo, o letramento digital, implica tanto a apropriação de uma tecnologia, quanto o exercício efetivo das práticas de escrita que circulam no meio digital.

A escrita colaborativa pode ser definida como um processo no qual autores com diferentes habilidades e responsabilidades interagem durante a elaboração de um documento. É um processo que exige gerar idéias, confrontá-las com os outros e entrar muitas vezes em negociações para chegar num consenso (MEDINA e FREITAS, 2004).

Na próxima seção, apontamos alguns resultados da ação com os professores e destes com seus alunos.

\section{Analisando a prática}

Os resultados da oficina utilizando o GoogleDocs foram bastante positivos. Conforme relato dos professores. O professor A comenta:

Eu não conhecia esta ferramenta ainda e adorei! Achei muito interessante deixar nossos arquivos salvos em ambiente de trabalho e ainda compartilhá-los com outras pessoas. Para a escola ele é de fundamental importância, pois assim conseguimos produzir diversos trabalhos, interagindo com nossos alunos de forma digital eficaz! [..] Além disso podemos interagir com outras escolas, por exemplo fazendo pesquisas, sondagens e até mesmo expondo os trabalhos realizados.

O professor B enfatiza que além do uso individual de várias formas também [...] pode acontecer de forma coletiva, em pequenos grupos ou até mesmo entre as escolas. E, complementando, o professor $\mathrm{C}$ destaca que: Esse recurso viabiliza a interação de arquivos seja nas empresas, escolas, grupos sociais, enfim em qualquer ambiente que tenha a necessidade de interação entre os membros.[...] favorece a integração com outras escolas através de atividades que envolvam os alunos e professores.

Diversas atividades podem ser desenvolvidas desde o Ensino Fundamental, passando pelo Ensino Médio (e até o Ensino Superior, ainda que não tenha sido o foco da ação analisada), através de produções envolvendo várias atividades distintas. Um dos desafios educacionais é acompanhar a dinâmica dos tempos modernos, por meio da integração com os novos recursos de linguagem, a exemplo dos editores de textos para produções textuais mais elaboradas, considerando também a influência que o texto exerce nos relacionamentos sociais. Koch (1998a, p. 128) sustenta: 
É preciso pensar a linguagem humana como lugar de interação, de constituição de identidades, de representação de papéis, de negociação de sentidos. É preciso encarar a linguagem humana não apenas como representação do mundo e do pensamento ou como instrumento de comunicação, mas sim, acima de tudo, como forma de inter-ação social.

O professor C ainda complementa [...] Em um mundo individualizado esse programa auxilia a escola a trabalhar com um ambiente onde a colaboração pode ser $o$ enfoque maior da aprendizagem. Já o professor D destaca [...] é muito bom para fazer textos colaborativos, trabalhos em grupo, pesquisas. Gostei muito deste recurso, muito interessante para compartilhar atividades e pesquisas.

Já o professor E conclui [...]

aprender a utilizar o Google Docs foi muito importante para todos do grupo, pois proporcionou, através das atividades, tanto em grupo como individuais, uma integração muito grande entre todos. Através desta ferramenta poderemos trabalhar de uma maneira diferente, proporcionando aos nossos alunos uma ampliação dos conhecimentos. O papel do aluno neste processo, acredito que seja de autor do seu próprio conhecimento, pois através dele poderão descobrir muitas coisas, interagir com os colegas da sua turma e também de outras.

Observa-se, pois, que ação com os professores despertou nos mesmos o interesse pelo uso da ferramenta Google Docs no processo de inclusão digital de seus alunos com destaque para atividades colaborativas e que promovam a interação.

Como mencionado anteriormente, a segunda etapa desta oficina refere-se às atividades desenvolvidas diretamente com alunos. $\mathrm{O}$ tempo previsto para $\mathrm{o}$ desenvolvimento também foi de 8 horas. Os professores utilizaram os laboratórios de suas escolas e alguns optaram em integrar as escolas num mesmo projeto.

Das atividades desenvolvidas com os alunos utilizando o GoogleDocs, destacamos algumas produções:

[1] utilizando o Editor de Textos: cartas escritas por um “químico” empregando termos utilizados em química e nomes de elementos químicos ( $9^{\circ}$ ano); produção de resenhas sobre Meio Ambiente ( $6^{\circ}$ ano); texto cooperativo sobre a Festa Junina da escola para interagir com alunos de outra escola ( $5^{\circ}$ ano); texto cooperativo sobre Sexualidade na adolescência ( $8^{\circ}$ ano); produção de poemas sobre Amizade ( $4^{\circ}$ ano); poemas sobre as obras de Tarsila do Amaral ( $6^{\circ}$ e $7^{\circ}$ ano). Segue uma das cartas produzidas.

Belírio Horizonte, zinco de cloro de 2011.

Querido Molibdênio,

Queria tântalo dizer que quebrei o hássio do meu braço quando estava tentando ligar o rádio em cima do gálio da casa do Túlio.

Fui ao hospital e me botaram um ferro e tálio no braço, eu nem conseguia calciar os sapatos. Passado um mês, tirei o ferro e o tálio do braço, e vi que a coisa estava cério. Pedi quanto ia custar; o médico disse que ia custar 100 pratas.

Cheguei em casa na Califórnio, pensando que estava curado, e dei um mercúrio na piscina, caí que nem um chumbo... Meu braço não estava no formiato certo ainda...

Mas o meu amigo Frâncio me salvou, só que me senti estanho, parecia que eu era um índio. 
E desde aquele
Ass: Neônio Boro Ósmio

Turma: 802

[2] utilizando o Editor de Apresentações: Viagem imaginária da 801 e 802: disciplina de Inglês -. organização de imagens e textos, pontos turísticos, dados sobre as capitais do Brasil ( $9^{\circ}$ ano); criação de slides informativos sobre Meio Ambiente ( $6^{\circ}$ ano); criação de slides com fotos sobre "O lugar onde moro" ( $8^{\circ}$ ano); criação de slides com imagens e textos sobre Cidadania ( $5^{\circ}$ ano).

Tema: Viagem imaginária da 801 e 802: disciplina de Inglês -. organização de imagens e textos, pontos turísticos, dados sobre as capitais do Brasil;

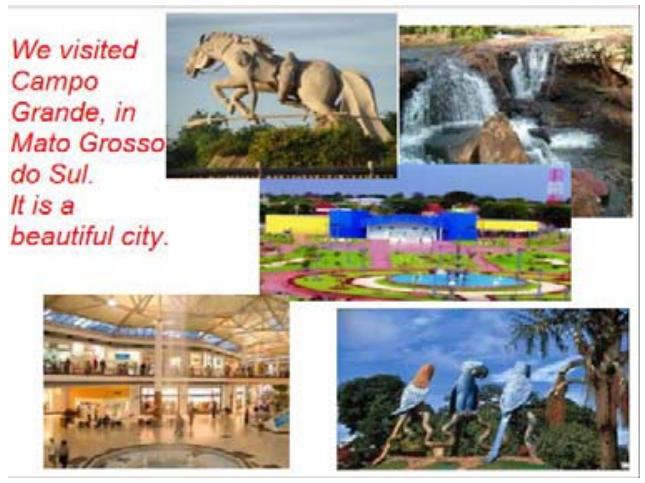

[3] utilizando o Editor de Formulários: elaboração e aplicação de entrevistas sobre a programação da televisão e jogos eletrônicos ( $7^{\circ}$ ano); criação de formulários sobre Meio Ambiente ( $6^{\circ}$ ano); elaboração de questionário sobre Drogas: ( $8^{\circ}$ ano).

[4] utilizando o Editor de Planilhas: dados e gráficos sobre meio Ambiente ( $6^{\circ}$ ano);

Ao todo, 262 alunos estiveram envolvidos nas atividades.

Quanto aos recursos físicos propostos por Warschauer (2006), considerandose os computadores e a conectividade: todas as escolas participantes possuem equipamentos que atendederm algumas das necessidades da ação. Uma das dificuldades apontadas pelos professores se refere ao Sistema Operacional instalado nos equipamentos. Alguns laboratórios possuem Linux Educacional, outros possuem Windows XP e outros ainda possuem os dois sistemas num mesmo laboratório. Mas,. No caso de ferramentas nas nuvens como foi o caso da usada nesta ação, esta dificuldade não se materializa. Outro fator que dificulta o andamento das atividades é a velocidade da Internet, apesar da banda larga. Conforme professor C, "A dificuldade ao realizar a atividade ficou por conta do acesso a internet. Com mais velocidade e o acesso de todos os alunos ao mesmo tempo é possível utilizar com mais sucesso essa ferramenta."

Em relação aos recursos digitais, considerados como conteúdo e linguagem, pôde-se perceber que a prática adotada na oficina de informática vem de encontro com conteúdos que norteiam as aulas. Trabalhar com esta ferramenta nos proporcionou ( $a$ nós e aos alunos) uma atividade bem interessante, a qual chamou a atenção das crianças, pois eles puderam interagir com colegas e observar como em outras escolas os trabalhos são feitos, como é o laboratório de informática em outras escolas, com o mesmo programa que eles tem. Foi um trabalho dinâmico, que teve um bom resultado. Esta é uma ferramenta que vamos utilizar diversas vezes, pois pode ser utilizada em 
qualquer nível escolar, desde a Educação Infantil até o Ensino Médio, e em qualquer disciplina, pois além de ser prática e proporcionar a portabilidade de arquivos, é de fácil acesso e dá bons resultados. A linguagem utilizada pelos professores busca uma aproximação do universo dos alunos, sendo, portanto adequada e propiciando envolvimento e afetividade na comunicação e interação.

Quanto aos recursos humanos, sob o enfoque do letramento e educação, a utilização das ferramentas do Google Docs, conforme professor I, apresentou para alunos uma solução para visualização de textos, planilhas de cálculo e apresentações eletrônicos nos mais diversos formatos, isso tudo on line, de qualquer lugar com acesso à rede, independente do pacote do office instalado no computador. A atividade é bastante interessante, a troca de trabalhos enriquece muito os alunos e os professores envolvidos. A práxis acontece naturalmente.

Quanto aos recursos sociais, vistos como comunidades e instituições, houve um envolvimento de parceria entre algumas escolas. Por exemplo as atividades sobre meio Ambiente, Elementos químicos, poemas e Festa Junina, o que ficou evidente no relato do professor G: "Durante o trabalho observou-se o interesse e dedicação dos alunos. Sentiam-se importantes por estarem postando suas idéias na rede e curiosos em saber o que os alunos de outras escolas pensavam sobre o assunto e sobre suas criações."

O professor I comentou ainda sobre a atividade dos poemas sobre as obras de Tarsila do Amaral que serão expostas nos transportes públicos do município que "a turma elegeu os melhores poemas para participarem de um concurso a nível municipal. Alunos de outras escolas através do compartilhamento leram os poemas eleitos pelo grande grupo."

Os apontamentos feitos pelos professores e o sucesso das ações com os alunos apontam pois para a pertinência do uso do Google Docs como ferramenta em ações de inclusão digital.

\section{Algumas considerações}

Os professores foram bastante participativos, curiosos e receberam muito bem a proposta quanto ao uso do Google Docs. Inicialmente foi explorado cada recurso com apresentação de exemplos de atividades desenvolvidas em diferentes níveis e disciplinas. A parte prática transcorreu dentro dos limites de velocidade de conexão internet deste laboratório. O fato de ficar sem conexão com frequência e, em alguns momentos, muito lento, mostra que é necessário melhorar as condições de infraestrutura. Além disso, as máquinas do laboratório usado com professores não eram todas iguais, não possuiam a mesma configuração, o que de certa forma também gerou descontentamento.

As vantagens no uso dos recursos do Google foram discutidos com o grupo. Apesar da facilidade de acessar os documentos de qualquer computador com acesso a internet, os professores comentaram que as escolas, mesmo estando no mesmo programa, ainda possuem realidades diferentes quanto a equipamentos e acesso a internet. O maior obstáculo surgiu pela falta de familiaridade, por parte dos alunos, com a utilização das ferramentas colaborativas que foi sendo facilmente ultrapassada no decorrer da sua utilização. Os alunos necessitam de um tempo de experimentação e 
reconhecimento das ferramentas e das suas funcionalidades. Dessa forma foi possível observar o início do desenvolvimento de competências do uso de TICs em atividades colaborativas conforme preconizado pela UNESCO (2009).

Outro registro é referente a disponibilidade dos computadores fora da escola alguns alunos não tem acesso a computador ou a internet fora do colégio. Estes alunos ficam restritos a atividades no período das aulas de informática. Assim, foi sugerido que fossem elaboradas atividades coletivas multidisciplinares de preferencia no período de aula, e/ou contraturno. Ampliar o acesso de alunos a computadores e Informática, portanto, no âmbito da escola, é uma forma de facilitar o processo de inclusão digital, o qual deve passar, neste caso, pela educação.

\section{Referências}

ANTONIO, José Carlos. Uso pedagógico do GoogleDocs, Professor Digital, SBO, 08 fev. 2010. Disponível em: <http://professordigital.wordpress.com/2010/02/08/usopedagogico-do-googledocs/>. Acesso em: outubro/2011

BUNGE, M. Sistemas Sociales y Filosofia. Buenos Aires: Ed. Sudamericana, 2a Edição, 1999.

CASTELLS, M. A Galáxia da Internet: reflexões sobre a internet, os negócios e a sociedade. Rio de Janeiro: Jorge Zahar Editor, 2003.

CETIC.br. Centro de Estudos sobre as Tecnologias da Informação e da Comunicação. Pesquisa Tic Domicílios 2010. Disponível em http://www.cetic.br/usuarios/tic/2010 Acesso setembro 2011

COSCARELLI, C. V. Alfabetização e Letramento Digital. In: COSCARELLI, C. V.; RIBEIRO, A. E. (Org.). Letramento Digital: aspectos sociais e possibilidades pedagógicas. Belo Horizonte: Ceale, Autêntica, 2005. p. 25-40.

GOULART, C. Letramento e Novas Tecnologias: questões para a prática pedagógica. In: COSCARELLI, C. V.; RIBEIRO, A. E. (Org.). Letramento Digital: aspectos sociais e possibilidades pedagógicas. Belo Horizonte: Ceale; Autêntica, 2005. p. 41-58.

KOCH, I. G. V. A Coesão Textual. 10. ed. São Paulo: Contexto, 1998a.

MEDINA, N. FREITAS, P. J.. Desenvolvimento do Pensamento Crítico na Escrita Colaborativa. RENOTE - Revista Novas Tecnologias na Educação, v. 2, n.2. 2004. Acesso mar. 2010.

THIOLlENT, Michel. Metodologia da Pesquisa-Ação - 15. ed. São Paulo: Cortez, 2007 (Coleção Temas Básicos de Pesquisa-Ação)

UNESCO. Padrões de competência em TIC para Professores: diretrizes de implementação. $2009 . \quad$ Disponível em: http://unesdoc.unesco.org/images/0015/001562/156209por.pdf . Acesso em novembro 2011

WARSCHAUER, M. (2006) Tecnologia e Inclusão Social: a exclusão digital em debate. São Paulo: Editora SENAC São Paulo. 